\title{
Distinct Cause of Death Profiles of Hospitalized Non-alcoholic Fatty Liver Disease: A 10 Years' Cross-Sectional Multicenter Study in China
}

\section{OPEN ACCESS}

Edited by:

Yeong Yeh Lee,

Universiti Sains Malaysia

(USM), Malaysia

Reviewed by:

Hakan Akin,

Marmara University, Turkey

María Jesús Perugorria,

Biodonostia Health Research Institute

(IIS Biodonostia), Spain

*Correspondence:

Bihui Zhong

zhongbh@mail.sysu.edu.cn

Junzhao Ye

yejzh@mail2.sysu.edu.cn

†These authors have contributed equally to this work

Specialty section

This article was submitted to

Gastroenterology,

a section of the journal

Frontiers in Medicine

Received: 17 July 2020 Accepted: 27 November 2020

Published: 12 January 2021

Citation:

Lin Y, Gong X, Li X, Shao C, Wu T,

Li M, Li F, Ma Q, Ye J and Zhong B (2021) Distinct Cause of Death Profiles of Hospitalized Non-alcoholic Fatty

Liver Disease: A 10 Years'

Cross-Sectional Multicenter Study in

China. Front. Med. 7:584396.

doi: 10.3389/fmed.2020.584396

\section{Yansong Lin ${ }^{1+}$, Xiaorong Gong ${ }^{2+}$, Xin $\mathrm{Li}^{3+}$, Congxiang Shao ${ }^{1}$, Tingfeng $\mathrm{Wu}^{1}{ }^{1}$, Minrui $\mathrm{Li}^{1}$,} Fuxi Li ${ }^{1}$, Qianqian Ma ${ }^{1}$, Junzhao $\mathrm{Ye}^{{ }^{*}}$ and Bihui Zhong ${ }^{1 *}$

${ }^{1}$ Department of Gastroenterology, The First Affiliated Hospital, Sun Yat-sen University, Guangzhou, China, ${ }^{2}$ Department of Gastroenterology, First Affiliated Hospital of Guangzhou Medical University, Guangzhou, China, ${ }^{3}$ Department of Gastroenterology, Affiliated Dongguan People's Hospital, Southern Medical University (Dongguan People's Hospital), Dongguan, China

Background: The clinical burden and natural history of non-alcoholic fatty liver disease (NAFLD) vary globally. We aimed to investigate NAFLD-related mortality profiles in hospitalized patients in southern China.

Methods: A multicenter retrospective investigation with a 10-year study period (2009-2018) analyzed 10,071 deaths during hospitalization (NAFLD: 2,015; other liver diseases: 1,140; without liver diseases: 6,916) was performed using a multiple cause of death analysis. Medical histories and biochemistry and imaging findings were extracted from the electronic medical record system. The underlying causes of death were classified by 10th Revision of the International Classification of Diseases (ICD-10) codes.

Results: The distribution of death causes in patients with NAFLD has stabilized over time, with cardio- and cerebral vascular disease (CVD) ranked first (35.6\%), followed by extrahepatic malignancies (22.6\%), infection (11.0\%), kidney disease (7.5\%), liver-related diseases (5.2\%), respiratory diseases (3.9\%), digestive diseases (3.5\%), endocrine diseases (3.5\%), and other diseases (7.2\%). NAFLD patients had more deaths attributable to CVD, extrahepatic malignancies, liver-related diseases (all $P<0.001$ ) and multiorgan failure than the deceased controls. The severity of steatosis was independently associated with these relationships (liver-related diseases: $\mathrm{OR}=1.37$, 95\% Cl: 1.20-1.59, cardio- and cerebrovascular diseases: OR $=1.23,95 \% \mathrm{Cl}$ : 1.19-1.31, infectious diseases: $\mathrm{OR}=1.14,95 \% \mathrm{Cl}: 1.04-1.26$, and renal diseases: $\mathrm{OR}=1.21,95 \% \mathrm{Cl}: 1.02-1.47$, all $P<0.05)$ after adjustment for sex, body mass index (BMI), fasting blood glucose, low-density lipoprotein cholesterol, uric acid, metabolic syndromes and fibrosis index based on the 4 factors.

Conclusion : NAFLD patients had higher proportions of death due to underlying CVD and liver-related diseases than the general population in China; these proportions positively correlated with steatosis degree.

Keywords: cause of death, non-alcoholic fatty liver disease, steatosis degree, multiorgan failure, real world study 


\section{INTRODUCTION}

Non-alcoholic fatty liver disease (NAFLD) has become the primary cause of chronic liver diseases in the last decade, affecting over one-fourth of the population worldwide (1). As one of the major drivers of hepatic mortality in developed countries (1-3), there is accumulating evidence that NAFLD is also responsible for extrahepatic system diseases. Epidemiologic data demonstrated that NAFLD was not only associated with a collection of metabolic syndrome components but also promoted the development of type 2 diabetes, cardiovascular disease (CVD) (4-6), osteoporosis, chronic kidney disease (7), chronic obstructive pulmonary disease $(8,9)$, pneumonia $(10)$, sleep apnea, urinary tract infection (11), gallstone disease (12), polycystic ovary syndrome, and malignant neoplasms (13) independently or via shared metabolic comorbidities (3).

Although NAFLD is strongly associated with and contributes to the clinical burden of such specific complications, whether it contributes to mortality due to distinct liver-related and extrahepatic diseases remains unknown (14-16). A recent metaanalysis reported that NAFLD increased overall mortality by $57 \%$ compared with the general population; mortality was mainly attributable to liver disease and CVD (17). Moreover, a recent meta-analysis including 25,837 patients from a six-cohort study demonstrated that the risk of clinical cardiovascular events was significantly higher in patients with NAFLD than in those without NAFLD (RR: 1.77 ; 95\% CI: 1.26-2.48, $P<0.001$ ) (18). However, in a more recent longitudinal study with a 10 -year follow-up in southern Asia, a lack of an association between NAFLD and cardiovascular mortality was reported (19). As most reports to date have utilized Gaussians, whether disparities in causes of death exist across ethnicities or regions remains unclear.

Epidemiological studies have indicated that the prevalence of NAFLD continues to increase in Asia (20), with the highest incidence predicted in China between 2016 and 2030 (21). The aforementioned studies suggested that Asian patients with NAFLD exhibited metabolic differences compared to Caucasians. Lean Asian people are more prone to metabolically obesity and insulin resistance than Europeans because they accumulate more adipose fat at an equivalent body mass. Moreover, genetic backgrounds, dietary habits, and lifestyles differ greatly between Western countries and Asia. The specific pattern of disease progression in Asian NAFLD populations has been limited by small sample sizes and short follow-up periods. Studies on the distribution of death causes in the disease course of Asian patients with NAFLD are scarce in Asia.

The aim of this study was to examine whether NAFLD was associated with a distinct spectrum of underlying causes of death in Chinese adults and to determine whether the degree of steatosis differentially influenced this relationship. Moreover, we also identified the clinical characteristics of patients with different causes of death in the setting of NAFLD.

\section{MATERIALS AND METHODS}

\section{Ethics}

The study involving human participants were reviewed and approved by Clinical Research Ethics Committee of the First
Affiliated Hospital of Sun Yat-sen University, the First Affiliated Hospital of Guangzhou Medical University, and the Affiliated Dongguan People's Hospital of Southern Medical University and written informed consent was obtained from all patients.

\section{Study Population and Design}

This was a retrospective survey utilizing a medical record review of consecutive hospitalization deaths from three tertiary university-affiliated medical centers in southern China (The First Affiliated Hospital of Sun Yat-sen University, The First Affiliated Hospital of Guangzhou Medical University, and the Affiliated Dongguan People's Hospital of Southern Medical University) from January 1, 2009, to December 31, 2018. The study was approved by the institutional and regional medical ethics committees. The inclusion criterion was patients aged over 18 years who underwent an abdominal ultrasonography (US) examination. Diagnosis of NAFLD were defined as those who met at least one of the three ultrasound criteria for fatty liver, and did not have excessive alcohol intake ( $>20 \mathrm{~g} /$ day in men and $>10 \mathrm{~g} /$ day in women) and negative markers of hepatitis $\mathrm{B}$ and C. Because steatosis can reduce or disappear during advanced fibrosis or cirrhosis development (22-25), and our study includes NAFLD patients retrospectively from multicenter using ultrasonography to establish diagnosis, part of NAFLD patients would progress to inflammation and fibrosis stage with steatosis degree decreased and they might be misclassified as cryptogenic cirrhosis due to the insufficient sensitivity of ultrasound, therefore cryptogenic cirrhosis would be ascribed to mild NAFLD in the analysis to avoid underestimation in this study. And we repeated our primary analyses after re-matching NAFLD patients by excluding cryptogenic cirrhosis, to address potential confounding. We excluded patients with secondary causes of fatty liver (e.g., long-term consumption of the steroids amiodarone, tamoxifen or methotrexate). Each death record was based on information extracted from the electronic database systems in the participating centers. The death certificates were derived from these death records from hospitals and confirmed by two physicians (X. G and X. L) that were blinded to the aim of this study independently according to the 10th revision of the International Statistical Classification of Diseases (ICD-10) codes, as recommended by the World Health Organization (WHO) (Supplementary Table 1). The contributing causes of death in this study were determined to be NAFLD, other liver diseases (i.e., viral hepatitis, autoimmune liver diseases, congenital liver diseases, hemochromatosis, iron overload, Wilson's disease, cholangitis, Budd-Chiari syndrome, and drug injury) and no liver disease (Levels of liver functions were within the normal range at the last admission before death, and the patients were without established diagnose of causes of liver disease according to the medical records from the hospitals). Causes of death were classified into liver-related, extrahepatic neoplasms, cardio- and cerebrovascular, infectious, respiratory, digestive, renal, endocrine diseases, and others, while liver-related deaths were defined as hepatocellular carcinoma (HCC) and cirrhotic complications, in accordance with the ICD10. Metabolic syndrome was based on International Diabetes Federation (2006) criteria. 
TABLE 1 | Baseline characteristics of the deaths with NAFLD and non-NAFLD.

\begin{tabular}{|c|c|c|c|c|c|c|c|}
\hline \multirow[t]{2}{*}{ Characteristics } & \multirow{2}{*}{$\begin{array}{c}\text { NAFLD } \\
(n=2,015)\end{array}$} & \multirow{2}{*}{$\begin{array}{l}\text { Other liver diseases } \\
\qquad(n=1,140)\end{array}$} & \multirow{2}{*}{$\begin{array}{l}\text { No liver diseases } \\
\quad(n=6,916)\end{array}$} & \multirow[t]{2}{*}{$P$} & \multicolumn{3}{|c|}{ Post-hoc } \\
\hline & & & & & NA vs. OL & NA vs. NL & OL vs. NL \\
\hline Male, $n(\%)$ & $1,099(54.5)$ & $819(71.8)$ & $4,248(61.4)$ & $<0.001$ & $<0.001$ & 0.015 & 0.003 \\
\hline Age, year & $64.4 \pm 18.9$ & $57.4 \pm 16.3$ & $66.1 \pm 19.2$ & $<0.001$ & $<0.001$ & 0.25 & $<0.001$ \\
\hline BMl, kg/m² & $24.3 \pm 5.5$ & $21.4 \pm 3.2$ & $21.6 \pm 3.6$ & $<0.001$ & $<0.001$ & $<0.001$ & 0.670 \\
\hline SBP, mmHg & $133.9 \pm 23.2$ & $125.4 \pm 24.7$ & $128.7 \pm 25.4$ & 0.002 & $<0.001$ & 0.016 & 0.063 \\
\hline $\mathrm{DBP}, \mathrm{mmHg}$ & $79.7 \pm 14.3$ & $75.1 \pm 15.5$ & $75.1 \pm 13.5$ & 0.080 & - & - & - \\
\hline$A L T, U / L^{a}$ & $31(16-50)$ & $51(25-80)$ & $31(17-52)$ & $<0.001$ & $<0.001$ & 0.32 & $<0.001$ \\
\hline$A S T, U / L^{a}$ & $44(24-71)$ & $108(69-168)$ & 49 (25-83) & $<0.001$ & $<0.001$ & 0.26 & $<0.001$ \\
\hline GGT, U/L & $64(31-104)$ & $63(32-103)$ & 53 (26-96) & $<0.001$ & 0.81 & 0.001 & 0.005 \\
\hline$A L P, U / L^{a}$ & $92(66-141)$ & $114(76-171)$ & $94(66-121)$ & $<0.001$ & 0.001 & 0.59 & $<0.001$ \\
\hline Total cholesterol, mmol/L & $5.28 \pm 1.29$ & $2.70 \pm 1.24$ & $3.53 \pm 1.17$ & $<0.001$ & $<0.001$ & $<0.001$ & $<0.001$ \\
\hline Triglycerides, mmol/L & $2.86 \pm 1.44$ & $0.99 \pm 0.46$ & $1.11 \pm 0.48$ & $<0.001$ & $<0.001$ & $<0.001$ & 0.950 \\
\hline HDL-cholesterol, mmol/L & $0.95 \pm 0.32$ & $0.63 \pm 0.25$ & $0.88 \pm 0.23$ & $<0.001$ & $<0.001$ & 0.006 & $<0.001$ \\
\hline LDL-cholesterol, mmol/L & $3.28 \pm 1.55$ & $1.69 \pm 0.88$ & $2.21 \pm 0.86$ & $<0.001$ & $<0.001$ & $<0.001$ & $<0.001$ \\
\hline Apolipoprotein-A1, g/L & $0.64 \pm 0.35$ & $1.00 \pm 0.38$ & $0.90 \pm 0.30$ & $<0.001$ & $<0.001$ & $<0.001$ & $<0.001$ \\
\hline Apolipoprotein-B, g/L & $0.97 \pm 0.36$ & $0.59 \pm 0.25$ & $0.71 \pm 0.22$ & $<0.001$ & $<0.001$ & $<0.001$ & $<0.001$ \\
\hline Lipoprotein-A, mg/L & $353.3 \pm 42.5$ & $161.2 \pm 23.7$ & $289.3 \pm 32.3$ & $<0.001$ & $<0.001$ & 0.007 & $<0.001$ \\
\hline FBG, mmol/L & $7.9 \pm 2.3$ & $6.4 \pm 1.5$ & $7.1 \pm 2.0$ & $<0.001$ & $<0.001$ & $<0.001$ & 0.014 \\
\hline Uric acid, umol/L & $368.7 \pm 40.6$ & $302.2 \pm 30.1$ & $334.4 \pm 32.4$ & $<0.001$ & $<0.001$ & 0.027 & 0.081 \\
\hline
\end{tabular}

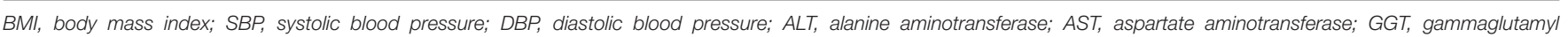

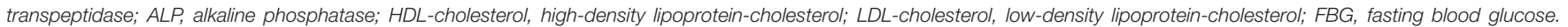
${ }^{a}$ Continuous variables are expressed as median with 25th-75th interquartile range for non-Gaussian distribution.

\section{Clinical Evaluation}

Baseline information collected during hospitalization but before treatment, including sex, age, race, and date of death, was extracted. Patient history data included demographics; past disorders; medication history; nicotine and alcohol consumption; and anthropometric measurements including body weight, body height, and blood pressure. Body mass index (BMI) was defined as the body weight in kilograms divided by the square of the body height in meters.

Serological examination data, including alanine transaminase (ALT), aspartate transaminase (AST), gamma-glutamyl transpeptidase (GGT), alkaline phosphatase (ALP), total cholesterol, triglycerides, high-density lipoprotein (HDL) cholesterol, low-density lipoprotein (LDL) cholesterol, fasting blood glucose (FBG), and uric acid, were assayed as mentioned previously. Metabolic syndrome is based on presence of at least 3 of 5 factors, which include triglycerides (TG) $150 \mathrm{mg} / \mathrm{dL}$ or greater, HDL cholesterol $<40 \mathrm{mg} / \mathrm{dL}$ in men and $<50 \mathrm{mg} / \mathrm{dL}$ in women, hypertension defined as systolic blood pressure 130 $\mathrm{mmHg}$ or greater or diastolic blood pressure $85 \mathrm{mmHg}$ or greater, hyperglycemia defined as fasting glucose $100 \mathrm{~g} / \mathrm{dL}$ or greater, and body mass index $25 \mathrm{~kg} / \mathrm{m}^{2}$ or greater (26). Fibrosis index based on the 4 factor (FIB-4) was calculated as FIB- $4=$ age $(\text { year })^{*} \operatorname{AST}(\mathrm{U} / \mathrm{L}) / \operatorname{PLT}\left(10^{9} / \mathrm{L}\right)^{*} \operatorname{ALT}(\mathrm{U} / \mathrm{L})^{0.5}$ (27).

\section{Radiologic Assessment and Steatosis Grading}

Fatty liver was evaluated with abdominal ultrasonography measurements within 1 year before death by experienced radiologists based on the following criteria: the presence of liver and kidney echo discrepancies, with or without the presence of posterior attenuation of the ultrasound beam, vessel blurring, and difficult visualization of the gallbladder wall and the diaphragm. Hepatic steatosis was further graded into 3 categories as follows: (1) mild steatosis, defined by the manifestation of diffusely increased echogenicity or hepatorenal contrast; (2) moderate steatosis, defined by the visualization of bright echoes and increased hepatorenal contrast concurrently; and (3) severe steatosis, defined by the observation of ultrasound beam attenuation based on the establishment of moderate steatosis.

\section{Statistical Analysis}

Normally distributed data are depicted as medians (standard deviations). The Kruskal-Wallis rank sum test was applied to abnormally distributed continuous variables between groups. Chi-square tests were used for comparisons of categorical data between groups, with Bonferroni post-hoc tests for multiple comparisons among subgroups. Logistic regression models with stepwise selection were used to estimate odds ratios (OR) for the different degrees of NAFLD in relation to the causes of death. A two-tailed $P<0.05$ was considered indicative of statistical significance. All data were analyzed using SPSS software (version 20.0, SPSS Inc., Chicago, IL, USA).

\section{RESULTS}

Between 2009 and 2018, there were 14,284 registered deaths during hospitalization. Ultrasound graphic assessment was performed in 10,071 cases $(61.2 \%$ males, aged $64.8 \pm 17.8$ 

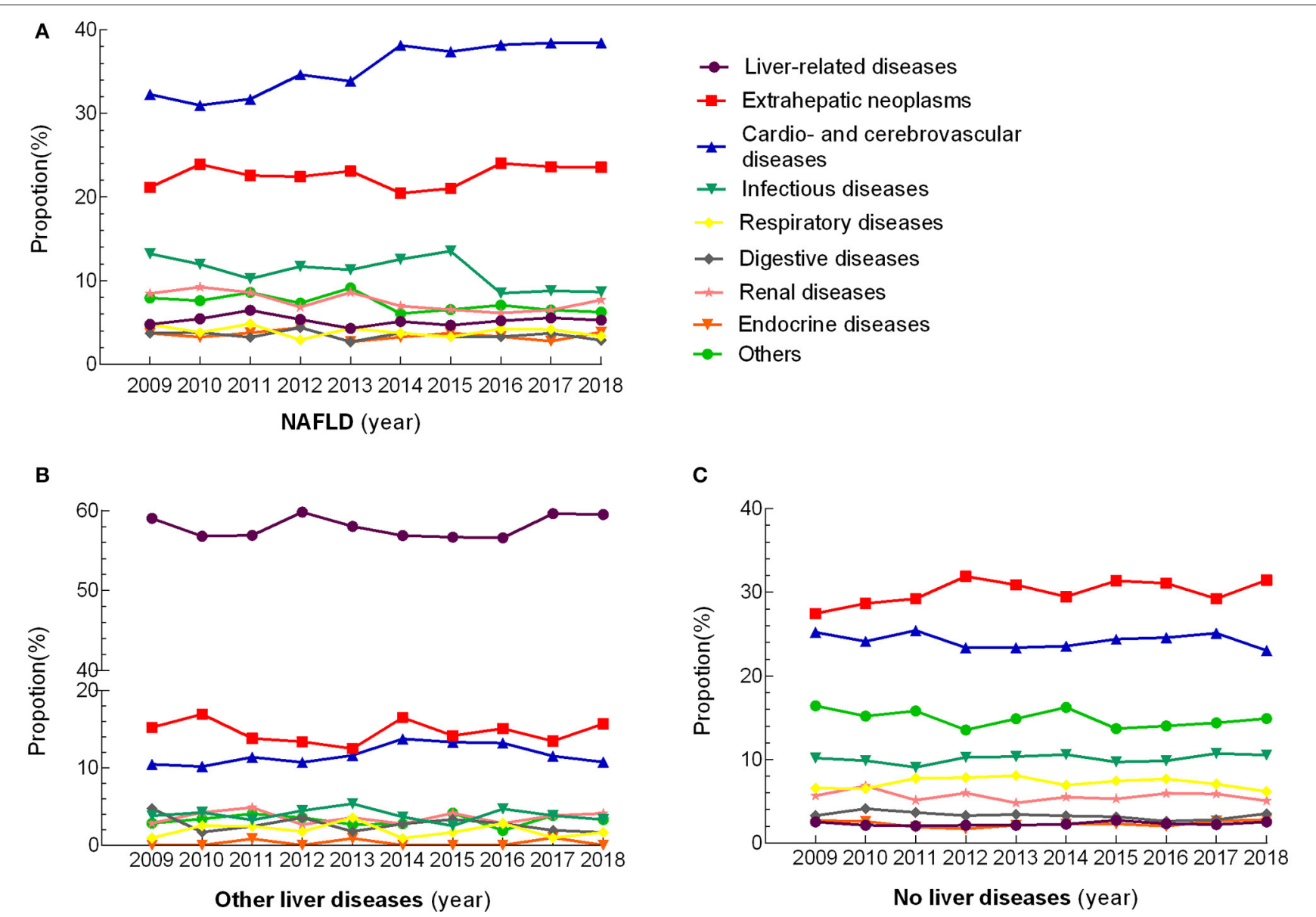

FIGURE 1 | Changing trends in the proportion of cause of death over 10 consecutive years. Every marker illustrated the proportion of death due to a different cause that was indicated as different colored lines.

years): 2,015 NAFLD (20.0\%, including 25 cases with cryptogenic cirrhosis), 1,140 other livers diseases (11.3\%), and 6,916 no liver disease $(68.7 \%)$, respectively. Lowest percentage of male appeared in the NAFLD groups $(54.5 \%, P<0.001)$, with the highest rate in the other liver disease group $(71.8 \%)$, followed by no liver disease group (61.4\%). Notedly, significant difference also existed in the mean age among the three groups was found (summarized in Table 1), with NAFLD and no liver diseases patients presenting a higher mean age to those with other liver diseases ( $64.4 \pm 18.9$ vs. $66.1 \pm 19.2$ vs. $57.4 \pm 16.3$ years, respectively). The NAFLD group presented higher BMI, systolic blood pressure (SBP), gamma-glutamyl transferase (GGT), total cholesterol, triglycerides, HDL cholesterol, LDL cholesterol, apolipoprotein-B, lipoprotein-A, fasting blood glucose, and uric acid but lower apolipoprotein-A1 levels than the no liver disease group (Table 1).

\section{Mortality Trends of NAFLD}

The distribution of death causes remained steady in the three groups over the decade (Figure 1). Within the NAFLD subgroups, the leading causes of mortality were categorized as CVDs (35.6\%), followed by extrahepatic tumors $(22.6 \%)$, infectious diseases (11.0\%), kidney disease (7.5\%), other diseases (7.2\%), liver-related diseases (5.2\%), respiratory diseases $(3.9 \%)$, digestive diseases (3.5\%), and endocrine diseases (3.5\%). A higher proportion of ischemic heart diseases was noted in NAFLD patients than in patients with other liver disease and without liver disease (21.6 vs. 4.0 vs. $14.7 \%, P<0.001)$, and similar trend presented in cerebrovascular disease ( 7.5 vs. 4.1 vs. $5.2 \%$ ) and chronic heart disease (4.3 vs. 1.2 vs. $2.9 \%$ ). Patients in the NAFLD group died from liver-related diseases significantly more frequently than those without liver diseases (5.2 vs. $2.3 \%$, $P<0.001$ ), but much less than those with other liver diseases (58.3\%, $P<0.001)$. For extrahepatic tumors, there was a stepwise increase among the other liver disease group, NAFLD group and no liver disease group (14.6 vs. 22.6 vs. $30.1 \%$, $P<0.001)$; however, for specific cancer types, colorectal cancer was overrepresented in with NAFLD than those with no liver diseases (6.2 vs. 5.0\%, $P=0.034$ ), while opposite trend was shown in lung ( 3.1 vs. $5.2 \%, P<0.001)$, and stomach cancer $(2.5$ vs. $4.1 \%, P=0.002)$, and no difference was found for hematologic cancer between these two groups ( 4.8 vs. $6.1 \%, P=0.06$ ). Among the deaths attributed to infectious diseases, pneumonia and sepsis were identified as the most prominent in the NAFLD patients; 
TABLE 2 | Cause of deaths in patients with NAFLD vs. non-NAFLD.

\begin{tabular}{|c|c|c|c|c|c|c|c|}
\hline \multirow[t]{2}{*}{ Diseases, $n$ (\%) } & \multirow{2}{*}{$\begin{array}{c}\text { NAFLD } \\
(n=2,015)\end{array}$} & \multirow{2}{*}{$\begin{array}{l}\text { Other liver diseases } \\
\qquad(n=1,140)\end{array}$} & \multirow{2}{*}{$\begin{array}{l}\text { No liver diseases } \\
\qquad(n=6,916)\end{array}$} & \multirow[t]{2}{*}{$P$} & \multicolumn{3}{|c|}{ Post-hoc } \\
\hline & & & & & NA vs. OL & NA vs. NL & OL vs. NL \\
\hline Liver-related diseases & $105(5.2)$ & $665(58.3)$ & 159 (2.3) & $<0.001$ & $<0.001$ & $<0.001$ & $<0.001$ \\
\hline Hepatocellular carcinoma & $51(2.5)$ & $327(28.7)$ & $104(1.5)$ & $<0.001$ & $<0.001$ & 0.004 & $<0.001$ \\
\hline Decompensated cirrhosis & $22(1.1)$ & $216(18.9)$ & $21(0.3)$ & $<0.001$ & $<0.001$ & $<0.001$ & $<0.001$ \\
\hline Hepatic failure & $32(1.6)$ & $122(10.7)$ & $34(0.5)$ & $<0.001$ & $<0.001$ & $<0.001$ & $<0.001$ \\
\hline Extrahepatic neoplasms & $455(22.6)$ & $166(14.6)$ & $2,082(30.1)$ & $<0.001$ & $<0.001$ & $<0.001$ & $<0.001$ \\
\hline Colorectal cancer & $125(6.2)$ & $45(3.9)$ & $346(5.0)$ & 0.024 & 0.013 & 0.034 & 0.190 \\
\hline Lung cancer & $62(3.1)$ & $30(2.6)$ & $360(5.2)$ & $<0.001$ & 0.570 & $<0.001$ & $<0.001$ \\
\hline Stomach cancer & $50(2.5)$ & $25(2.2)$ & $284(4.1)$ & $<0.001$ & 0.710 & 0.002 & 0.006 \\
\hline Hematologic malignancy & $97(4.8)$ & $41(3.6)$ & $422(6.1)$ & 0.001 & 0.310 & 0.060 & 0.004 \\
\hline Other malignancies & $121(6.0)$ & $25(2.2)$ & $670(9.7)$ & $<0.001$ & $<0.001$ & $<0.001$ & $<0.001$ \\
\hline Cardio- and cerebrovascular diseases & $717(35.6)$ & $132(11.6)$ & $1,674(24.2)$ & $<0.001$ & $<0.001$ & $<0.001$ & $<0.001$ \\
\hline Ischemic heart disease & $436(21.6)$ & $46(4.0)$ & $1,017(14.7)$ & $<0.001$ & $<0.001$ & $<0.001$ & $<0.001$ \\
\hline Cerebrovascular disease & $151(7.5)$ & $47(4.1)$ & $360(5.2)$ & $<0.001$ & $<0.001$ & $<0.001$ & 0.374 \\
\hline Chronic heart disease & $86(4.3)$ & $14(1.2)$ & $200(2.9)$ & $<0.001$ & $<0.001$ & 0.004 & 0.004 \\
\hline Others & $44(2.2)$ & $25(2.2)$ & $97(1.4)$ & 0.013 & 0.880 & 0.026 & 0.058 \\
\hline Infectious diseases & $222(11.0)$ & $44(3.9)$ & $699(10.1)$ & $<0.001$ & $<0.001$ & 0.470 & $<0.001$ \\
\hline Pneumonia or sepsis & $136(6.7)$ & $30(2.6)$ & $436(6.3)$ & $<0.001$ & $<0.001$ & 0.950 & $<0.001$ \\
\hline Aspergillosis & $58(2.9)$ & $8(0.7)$ & $187(2.7)$ & $<0.001$ & $<0.001$ & 0.670 & $<0.001$ \\
\hline Tuberculosis & $12(0.6)$ & $3(0.3)$ & $41(0.6)$ & 0.402 & - & - & - \\
\hline Others & $16(0.8)$ & $3(0.3)$ & $35(0.5)$ & 0.132 & - & - & - \\
\hline Respiratory diseases & 79 (3.9) & $22(2.0)$ & $498(7.2)$ & $<0.001$ & 0.008 & $<0.001$ & $<0.00$ \\
\hline Chronic obstructive pulmonary diseases & $50(2.5)$ & $11(1.0)$ & $325(4.7)$ & $<0.001$ & 0.008 & $<0.001$ & $<0.001$ \\
\hline Pulmonary arterial hypertension & $16(0.8)$ & $5(0.5)$ & $104(1.5)$ & 0.002 & 0.530 & 0.030 & 0.010 \\
\hline Lung fibrosis & $5(0.2)$ & $3(0.3)$ & $27(0.4)$ & 0.570 & - & - & - \\
\hline Others & $8(0.4)$ & $3(0.3)$ & $42(0.6)$ & 0.240 & - & - & - \\
\hline Digestive diseases & $70(3.5)$ & $30(2.7)$ & $228(3.3)$ & 0.520 & - & - & - \\
\hline Pancreatitis & $38(1.9)$ & $15(1.4)$ & $124(1.8)$ & 0.580 & - & - & - \\
\hline Upper gastrointestinal hemorrhage & $24(1.2)$ & $11(1.0)$ & $83(1.2)$ & 0.840 & - & - & - \\
\hline Others & $8(0.4)$ & $4(0.4)$ & $21(0.3)$ & 0.800 & - & - & - \\
\hline Renal diseases & $151(7.5)$ & $41(3.7)$ & $387(5.6)$ & $<0.001$ & $<0.001$ & 0.004 & 0.020 \\
\hline Chronic kidney diseases & $78(3.9)$ & $23(2.1)$ & $214(3.1)$ & 0.020 & 0.014 & 0.170 & 0.130 \\
\hline Acute kidney injury & $59(2.9)$ & $15(1.4)$ & $138(2.0)$ & 0.007 & 0.012 & 0.024 & 0.310 \\
\hline Others & $14(0.7)$ & $3(0.3)$ & $35(0.5)$ & 0.280 & - & - & - \\
\hline Endocrine diseases & $70(3.5)$ & $3(0.3)$ & $159(2.3)$ & $<0.001$ & $<0.001$ & 0.006 & $<0.001$ \\
\hline Diabetes mellitus & $46(2.3)$ & $2(0.2)$ & $97(1.4)$ & $<0.001$ & $<0.001$ & 0.012 & 0.002 \\
\hline Thyrotoxicosis & $15(0.7)$ & $1(0.1)$ & $41(0.6)$ & 0.060 & - & - & - \\
\hline Others & $9(0.4)$ & $0(0)$ & $21(0.3)$ & 0.091 & - & - & - \\
\hline Others & $146(7.2)$ & $37(3.4)$ & $1,030(14.9)$ & $<0.001$ & $<0.001$ & $<0.001$ & $<0.001$ \\
\hline
\end{tabular}

NA, NAFLD; OL, Other liver diseases; NL, No liver diseases.

Chi-squared test for the comparison of cause of deaths distribution between NAFLD and non-NAFLD.

they were more common in NAFLD patients than in those with other liver diseases and similar in those without liver diseases (6.7 vs. 2.6 vs. $6.3 \%$ ) (Table 2). Analyzing the data according to sex showed that deaths attributed to liver-related diseases occurred more frequently in males $(P<0.001)$ and deaths attributed to endocrine diseases occurred more frequently in females $(P<$ 0.001 ) in the NAFLD group, while the other causes of death showed no significant sex differences; this trend was similar in the other liver diseases group $(P<0.001$ for liver-related diseases and $P=0.006$ for endocrine diseases). Sex difference was found for those without liver diseases in any of the subgroups except for the infectious disease (Supplementary Table 2).

\section{Obesity and Causes of Death in NAFLD}

To examine the effect of obesity on cause of death, we stratified the patients into obese and non-obese group, defined based on BMI $\geq 25$ and $<25 \mathrm{~kg} / \mathrm{m}^{2}$, respectively. Deaths attributed to cardio- and cerebrovascular diseases occurred more frequently in 
TABLE 3 | Association between steatosis degrees and distribution of causes of death.

\begin{tabular}{|c|c|c|c|c|c|c|c|c|}
\hline \multirow[t]{2}{*}{ Diseases, $n$ (\%) } & \multirow{2}{*}{$\begin{array}{l}\text { Non-NAFLD } \\
(n=6,916)\end{array}$} & \multirow{2}{*}{$\begin{array}{l}\text { Mild } \\
(n=565)\end{array}$} & \multirow{2}{*}{$\begin{array}{l}\text { Moderate } \\
(n=1,102)\end{array}$} & \multirow{2}{*}{$\begin{array}{l}\text { Severe } \\
(n=348)\end{array}$} & \multicolumn{2}{|c|}{ Univariate } & \multicolumn{2}{|c|}{ Multivariate } \\
\hline & & & & & OR $(95 \% \mathrm{Cl})$ & $\boldsymbol{P}$ & OR $(95 \% \mathrm{Cl})$ & $\boldsymbol{P}$ \\
\hline Liver-related diseases & $159(2.3)$ & $24(4.2)$ & $61(5.5)$ & $20(5.7)$ & $1.35(1.17-1.57)$ & $<0.001$ & $1.37(1.20-1.59)$ & $<0.001$ \\
\hline Extrahepatic neoplasms & $2,082(30.1)$ & $182(32.2)$ & $228(20.7)$ & 45 (12.9) & $0.92(0.82-0.99)$ & 0.001 & $0.96(0.83-1.02)$ & 0.160 \\
\hline Cardio- and cerebrovascular diseases & $1,674(24.2)$ & $209(37.0)$ & $394(35.8)$ & $114(32.8)$ & $1.22(1.16-1.30)$ & $<0.001$ & $1.23(1.19-1.31)$ & $<0.001$ \\
\hline Infectious diseases & $699(10.1)$ & $56(9.9)$ & $104(9.4)$ & $62(17.8)$ & $1.16(1.02-1.36)$ & 0.025 & $1.14(1.04-1.26)$ & 0.035 \\
\hline Respiratory diseases & $498(7.2)$ & $28(4.9)$ & $40(3.6)$ & $11(3.2)$ & $0.86(0.79-0.96)$ & 0.020 & 0.89 (0.78-0.98) & 0.250 \\
\hline Digestive diseases & 228 (3.3) & $18(3.2)$ & $35(3.2)$ & $17(4.9)$ & 1.03 (0.81-1.36) & 0.780 & 1.05 (0.79-1.38) & 0.680 \\
\hline Renal diseases & $387(5.6)$ & $18(3.2)$ & $110(10.0)$ & $23(6.6)$ & $1.19(1.01-1.45)$ & 0.045 & $1.21(1.02-1.47)$ & 0.043 \\
\hline Endocrine diseases & $159(2.3)$ & $11(1.9)$ & $43(3.9)$ & $16(4.6)$ & $1.18(0.92-1.57)$ & 0.540 & $1.15(0.89-1.54)$ & 0.440 \\
\hline Others & $1,030(14.9)$ & $19(3.4)$ & $87(7.9)$ & $40(11.5)$ & $0.89(0.79-1.01)$ & 0.051 & $0.88(0.77-0.99)$ & 0.042 \\
\hline
\end{tabular}

FIB-4, fibrosis index based on the 4 factor; FIB-4 = age (year) $)^{*} A S T(U / L) / P L T\left(10^{9} / L\right)^{*} A L T(U / L)^{0} .5$.

Multivariate logistics regression analysis adjusted for sex, body mass index, fasting blood glucose, low-density lipoprotein cholesterol, uric acid metabolic syndrome and FIB-4. Non-NAFLD group was used as reference for this analysis.

the obese with NAFLD (35.6 vs. $30.3 \%, P<0.001)$, while opposite trend was shown in NAFLD group dying from infectious diseases (11.1 vs. $13.4 \%, P<0.001$ ) and renal diseases (6.1 vs. $8.7 \%$, $P=0.027)$. The other causes of death showed no significant differences in term of BMI (Supplementary Table 3).

\section{Associations Among Steatosis Grade, Advanced Fibrosis and Causes of Mortality}

In the subjects with NAFLD, the degree of hepatic steatosis was further assessed by abdominal ultrasound as mild (565 cases, $28.0 \%$ ), moderate (1,102 cases, $54.7 \%$ ), or severe (348 cases, 17.3\%). After multiple adjustments for sex, body mass index, fasting blood glucose, low-density lipoprotein cholesterol, uric acid, metabolic syndrome, and FIB-4 index, the binary logistic regression analysis indicated that the steatosis degree increase was associated with an increased risk of death from liver-related diseases $(\mathrm{OR}=1.37,95 \% \mathrm{CI}: 1.20-1.59, P<0.001)$, cardioand cerebrovascular diseases $(\mathrm{OR}=1.23,95 \% \mathrm{CI}: 1.19-1.31$, $P<0.001)$, infectious diseases(OR $=1.14,95 \%$ CI: $1.04-1.26$, $P=0.035)$, and renal diseases (OR $=1.21$, 95\% CI: $1.02-$ 1.47, $P=0.043$ ), while the other causes of death showed no significant association with NAFLD severity (Table 3). In NAFLD group, subjects with advanced fibrosis predicted by FIB-4 (cut-off value $=1.3$ ) significantly more frequently died from liver-related diseases $(P<0.001)$, extrahepatic neoplasms $(P=0.043)$, cardioand cerebrovascular diseases $(P=0.038)$, and infectious diseases $(P=0.010)$ (Supplementary Table 4).

\section{Characteristics of Different Causes of Deaths With NAFLD}

The anthropometrical and metabolic characteristics of different causes of death in the NAFLD group are presented in Table 4. Significant differences in age, sex, BMI, and SBP or diastolic blood pressure (DBP) were found among the different causes. Regarding hepatic markers and metabolic characteristics among the different causes, ALT, AST, ALP, total cholesterol, triglycerides, HDL cholesterol, LDL cholesterol, apolipoprotein$A 1$, and lipoprotein-A showed significant differences, while GGT, FBG, uric acid and apolipoprotein-B did not show significant differences.

\section{Relation Between NAFLD and Multiple Organ Dysfunction Syndrome (MODS)}

The occurrence of multiple organ dysfunction syndrome (MODS) among the three groups during death was calculated. A total of 877 cases of heart failure $(43.5 \%)$, followed by respiratory failure $(43.9 \%)$, renal failure $(32.5 \%)$, hepatic failure $(13.2 \%)$, and disseminated intravascular coagulation (12.6\%) occurred in the NAFLD group, with all the organ dysfunctions being more prevalent in the NAFLD group than the other two groups except for the hepatic failure. NAFLD patients had significantly higher prevalence rates of two organ dysfunctions ( 15.5 vs. $9.5 \%$, $P<0.001$ ) than the no liver disease group, but these rates were not significantly different from those in the other liver disease group $(P=0.09)$. Finally, the presence of MODS was highest ( 29.6 vs. $25.8 \%$ in other liver disease vs. $21.6 \%$ in no liver disease, $P<0.001$ ) than that in the other groups (Table 5).

\section{Sensitivity Anlyses}

Data using another NAFLD subset which censored cryptogenic cirrhosis was exhibited in Supplementary Tables 5-12). The results were similar to that using cryptogenic cirrhosis as definition of mild NAFLD, and we observed a similar, dosedependent association between steatosis degree and specific death causes proportions, as well as increased MODS.

\section{DISCUSSION}

Liver disease is the 12th leading cause of death worldwide, and there is a substantial increase related to NAFLD in liverrelated mortality (16). Using 10 years of regional representative mortality data with over 10,000 samples in southern China, we presented a comprehensive analysis of NAFLD-specific 
TABLE 4 | Anthropometrical and metabolic characteristics of different causes of deaths with NAFLD.

\begin{tabular}{|c|c|c|c|c|c|c|c|c|c|c|}
\hline Characteristics & $\begin{array}{l}\text { Liver-related } \\
\text { diseases } \\
\quad(n=105)\end{array}$ & $\begin{array}{c}\text { Extrahepatic } \\
\text { neoplasms } \\
(n=455)\end{array}$ & $\begin{array}{l}\text { Cardio-and } \\
\text { cerebrovascular } \\
\text { diseases } \\
(n=717)\end{array}$ & $\begin{array}{l}\text { Infectious } \\
\text { diseases } \\
(n=222)\end{array}$ & $\begin{array}{l}\text { Respiratory } \\
\text { diseases } \\
(n=79)\end{array}$ & $\begin{array}{c}\text { Digestive } \\
\text { diseases } \\
(n=70)\end{array}$ & $\begin{array}{c}\text { Renal } \\
\text { diseases } \\
(n=151)\end{array}$ & $\begin{array}{l}\text { Endocrine } \\
\text { diseases } \\
(n=70)\end{array}$ & $\begin{array}{l}\text { Others } \\
(n=146)\end{array}$ & $\boldsymbol{P}$ \\
\hline Male, $n(\%)$ & $\begin{array}{l}78(74.3) \\
\text { bcdefgh }\end{array}$ & $\begin{array}{c}242(53.2) \\
\text { ahi }\end{array}$ & $\begin{array}{c}401 \text { (55.9) } \\
\text { ahi }\end{array}$ & $\begin{array}{c}136(61.3) \\
\text { aghi }\end{array}$ & $\begin{array}{c}47(59.5) \\
\text { ahi }\end{array}$ & $\begin{array}{c}35 \text { (50.0) } \\
\text { adhi }\end{array}$ & $\begin{array}{c}77 \text { (51.0) } \\
\text { adhi }\end{array}$ & $\begin{array}{c}23(32.9) \\
\text { abcdefg }\end{array}$ & $\begin{array}{l}58(39.7) \\
\text { abcdefg }\end{array}$ & $<0.001$ \\
\hline Age, year & $\begin{array}{c}54.0 \pm 17.8 \\
\text { bcdefgh }\end{array}$ & $\begin{array}{c}65.5 \pm 16.4 \\
\text { aghi }\end{array}$ & $\begin{array}{c}70.0 \pm 15.8 \\
\text { agi }\end{array}$ & $\begin{array}{c}66.4 \pm 19 \\
\text { agi }\end{array}$ & $\begin{array}{c}64.9 \pm 18.6 \\
\text { aghi }\end{array}$ & $\begin{array}{c}64.5 \pm 19.6 \\
\text { aghi }\end{array}$ & $\begin{array}{l}59.2 \pm 21.0 \\
\text { abcdefh }\end{array}$ & $\begin{array}{c}71.2 \pm 14.0 \\
\text { abefgi }\end{array}$ & $\begin{array}{l}56.8 \pm 20.3 \\
\text { bcdefh }\end{array}$ & $<0.001$ \\
\hline $\mathrm{BMI}, \mathrm{kg} / \mathrm{m}^{2}$ & $\begin{array}{c}27.1 \pm 3.8 \\
\mathrm{bg}\end{array}$ & $\begin{array}{c}22.8 \pm 4.2 \\
\text { afh }\end{array}$ & $\begin{array}{c}24.4 \pm 4.8 \\
\text { gh }\end{array}$ & $\begin{array}{c}24.6 \pm 6.3 \\
\text { gh }\end{array}$ & $\begin{array}{c}25.3 \pm 7.8 \\
\text { gh }\end{array}$ & $\begin{array}{c}25.8 \pm 5.0 \\
\text { bgh }\end{array}$ & $\begin{array}{c}21.2 \pm 3.3 \\
\text { acdefhi }\end{array}$ & $\begin{array}{c}30.4 \pm 8.2 \\
\text { bcdefgi }\end{array}$ & $\begin{array}{c}24.4 \pm 4.7 \\
\text { gh }\end{array}$ & 0.038 \\
\hline $\mathrm{SBP}, \mathrm{mmHg}$ & $\begin{array}{l}130.5 \pm 16.0 \\
\text { cd }\end{array}$ & $\begin{array}{l}129.4 \pm 10.5 \\
\text { eghi }\end{array}$ & $\begin{array}{c}149.3 \pm 21.8 \\
\text { abdefhi }\end{array}$ & $\begin{array}{c}129.6 \pm 10.4 \\
\text { bcfgh }\end{array}$ & $\begin{array}{c}136.3 \pm 19.0 \\
\text { abcfgh }\end{array}$ & $\begin{array}{c}130.6 \pm 11.9 \\
\text { cdegh }\end{array}$ & $\begin{array}{c}148.8 \pm 23.6 \\
\text { abdefhi }\end{array}$ & $\begin{array}{c}159.0 \pm 18.1 \\
\text { abcdefgi }\end{array}$ & $\begin{array}{c}133.0 \pm 10.8 \\
\text { cgh }\end{array}$ & $<0.001$ \\
\hline DBP, $\mathrm{mmHg}$ & $\begin{array}{c}80.6 \pm 8.2 \\
\text { gh }\end{array}$ & $\begin{array}{l}75.9 \pm 7.2 \\
\text { cefgh }\end{array}$ & $\begin{array}{c}85.8 \pm 9.8 \\
\text { bdi }\end{array}$ & $\begin{array}{c}75.7 \pm 8.9 \\
\text { cfgh }\end{array}$ & $\begin{array}{c}79.3 \pm 7.3 \\
\text { bgh }\end{array}$ & $\begin{array}{c}83.0 \pm 9.6 \\
\text { bdghi }\end{array}$ & $\begin{array}{c}89.0 \pm 9.2 \\
\text { abdefi }\end{array}$ & $\begin{array}{l}88.7 \pm 9.9 \\
\text { abdefi }\end{array}$ & $\begin{array}{c}77.8 \pm 8.1 \\
\text { cfgh }\end{array}$ & $<0.001$ \\
\hline $\mathrm{ALT}, \mathrm{U} / \mathrm{L}^{\dagger}$ & $\begin{array}{c}55 \text { (33-65) } \\
\text { bcdefghi }\end{array}$ & $\begin{array}{l}29(16-43) \\
\quad \text { adg }\end{array}$ & $\begin{array}{c}29(16-46) \\
\quad \text { adg }\end{array}$ & $\begin{array}{l}41(17-65) \\
\text { abcefghi }\end{array}$ & $\begin{array}{l}27 \text { (16-38) } \\
\quad \text { adg }\end{array}$ & $\begin{array}{l}23(14-40) \\
\text { adghi }\end{array}$ & $\begin{array}{c}20 \text { (9-28)a } \\
\text { bcdefhi }\end{array}$ & $\begin{array}{c}32(11-50) \\
\text { adfg }\end{array}$ & $\begin{array}{c}33(15-50) \\
\text { adfg }\end{array}$ & $<0.001$ \\
\hline AST, $\mathrm{U} / \mathrm{L}^{\dagger}$ & $\begin{array}{c}112(67-160) \\
\text { bcdefghi }\end{array}$ & $\begin{array}{c}49 \text { (24-73) } \\
\text { acdefg }\end{array}$ & $\begin{array}{c}38 \text { (23-53) } \\
\text { abdhi }\end{array}$ & $\begin{array}{c}60 \text { (28-88) } \\
\text { abcefghi }\end{array}$ & $\begin{array}{c}37 \text { (24-50) } \\
\text { abdhi }\end{array}$ & $\begin{array}{c}33 \text { (22-44) } \\
\text { abdhi }\end{array}$ & $\begin{array}{c}30 \text { (19-45) } \\
\text { abdhi }\end{array}$ & $\begin{array}{c}48(24-80) \\
\text { acdefg }\end{array}$ & $\begin{array}{c}47 \text { (25-72) } \\
\text { acdefg }\end{array}$ & $<0.001$ \\
\hline GGT, U/L ${ }^{\dagger}$ & $101(35-158)$ & $73(31-110)$ & $56(30-78)$ & 74 (35-105) & $53(32-75)$ & $51(26-75)$ & $43(30-55)$ & $53(22-78)$ & $69(30-89)$ & 0.330 \\
\hline$A L P, U / L^{\dagger}$ & $\begin{array}{c}187 \text { (113-255) } \\
\text { bcdefghi }\end{array}$ & $\begin{array}{c}113(68-154) \\
\text { acdeghi }\end{array}$ & $\begin{array}{c}82(63-101) \\
\text { abdefi }\end{array}$ & $\begin{array}{c}130 \text { (83-167) } \\
\text { abcefghi }\end{array}$ & $\begin{array}{c}89 \text { (68-110) } \\
\text { abcdfg }\end{array}$ & $\begin{array}{c}111(67-150) \\
\text { acdeghi }\end{array}$ & $\begin{array}{c}74 \text { (53-100) } \\
\text { abdefhi }\end{array}$ & $\begin{array}{c}84 \text { (63-105) } \\
\text { abdfg }\end{array}$ & $\begin{array}{c}92(65-118) \\
\text { abcdfg }\end{array}$ & $<0.001$ \\
\hline Total cholesterol, mmol/L & $\begin{array}{c}5.7 \pm 1.4 \\
\text { defi }\end{array}$ & $\begin{array}{c}5.7 \pm 1.4 \\
\text { defi }\end{array}$ & $\begin{array}{c}5.5 \pm 1.0 \\
\text { dei }\end{array}$ & $\begin{array}{l}4.3 \pm 1.0 \\
\text { abcefghi }\end{array}$ & $\begin{array}{l}5.0 \pm 0.9 \\
\text { abcdfgh }\end{array}$ & $\begin{array}{c}3.7 \pm 1.2 \\
\text { abdeghi }\end{array}$ & $\begin{array}{c}5.5 \pm 1.1 \\
\text { defi }\end{array}$ & $\begin{array}{c}5.5 \pm 1.5 \\
\text { defi }\end{array}$ & $\begin{array}{l}4.8 \pm 1.3 \\
\text { abcdfgh }\end{array}$ & 0.001 \\
\hline Triglycerides, mmol/L & $\begin{array}{c}2.5 \pm 1.5 \\
\text { bdefgi }\end{array}$ & $\begin{array}{l}2.7 \pm 1.0 \\
\text { acdhi }\end{array}$ & $\begin{array}{c}2.5 \pm 1.2 \\
\text { bdefgi }\end{array}$ & $\begin{array}{l}3.8 \pm 1.2 \\
\text { abcefh }\end{array}$ & $\begin{array}{l}2.8 \pm 1.0 \\
\text { acdhi }\end{array}$ & $\begin{array}{c}3.0 \pm 1.1 \\
\text { acdhi }\end{array}$ & $\begin{array}{c}3.4 \pm 1.5 \\
\text { ach }\end{array}$ & $\begin{array}{c}2.4 \pm 1.4 \\
\text { bdefgi }\end{array}$ & $\begin{array}{c}3.8 \pm 2.4 \\
\text { abcefh }\end{array}$ & 0.006 \\
\hline HDL-cholesterol, mmol/L & $\begin{array}{c}0.71 \pm 0.17 \\
\text { bceg }\end{array}$ & $\begin{array}{c}1.04 \pm 0.25 \\
\text { adfi }\end{array}$ & $\begin{array}{c}1.08 \pm 0.22 \\
\text { adfi }\end{array}$ & $\begin{array}{c}0.74 \pm 0.14 \\
\text { bcef }\end{array}$ & $\begin{array}{c}1.22 \pm 0.22 \\
\text { adfi }\end{array}$ & $\begin{array}{c}0.54 \pm 0.15 \\
\text { bcdeghi }\end{array}$ & $\begin{array}{c}0.99 \pm 0.21 \\
\text { afi }\end{array}$ & $\begin{array}{c}1.06 \pm 0.22 \\
\mathrm{dfi}\end{array}$ & $\begin{array}{c}0.74 \pm 0.12 \\
\text { bcefgh }\end{array}$ & $<0.001$ \\
\hline LDL-cholesterol, mmol/L & $\begin{array}{c}3.62 \pm 1.19 \\
\mathrm{dfi}\end{array}$ & $\begin{array}{c}3.55 \pm 1.29 \\
\mathrm{dfi}\end{array}$ & $\begin{array}{c}3.45 \pm 1.09 \\
\mathrm{dfi}\end{array}$ & $\begin{array}{c}2.50 \pm 1.1 \\
\text { abcegh }\end{array}$ & $\begin{array}{c}3.50 \pm 1.17 \\
\mathrm{dfi}\end{array}$ & $\begin{array}{c}2.24 \pm 0.52 \\
\text { abcegh }\end{array}$ & $\begin{array}{c}3.26 \pm 1.61 \\
\text { df }\end{array}$ & $\begin{array}{c}3.55 \pm 1.14 \\
\text { dfi }\end{array}$ & $\begin{array}{c}2.84 \pm 0.64 \\
\text { abceh }\end{array}$ & $<0.001$ \\
\hline Apolipoprotein-A1, g/L & $\begin{array}{c}0.65 \pm 0.36 \\
\text { cegh }\end{array}$ & $\begin{array}{c}0.97 \pm 0.51 \\
\text { cef }\end{array}$ & $\begin{array}{c}1.16 \pm 0.44 \\
\text { abdfi }\end{array}$ & $\begin{array}{l}0.79 \pm 0.45 \\
\text { cefgh }\end{array}$ & $\begin{array}{c}1.24 \pm 0.48 \\
\text { abdfi }\end{array}$ & $\begin{array}{c}0.6 \pm 0.24 \\
\text { bcdeghi }\end{array}$ & $\begin{array}{c}1.08 \pm 0.44 \\
\text { adf }\end{array}$ & $\begin{array}{c}1.12 \pm 0.35 \\
\text { adf }\end{array}$ & $\begin{array}{c}0.81 \pm 0.43 \\
\text { cef }\end{array}$ & $<0.001$ \\
\hline Apolipoprotein-B, g/L & $0.91 \pm 0.39$ & $1.03 \pm 0.35$ & $0.99 \pm 0.34$ & $0.87 \pm 0.28$ & $0.97 \pm 0.24$ & $0.67 \pm 0.40$ & $0.97 \pm 0.24$ & $1.06 \pm 0.26$ & $1.05 \pm 0.25$ & 0.150 \\
\hline Lipoprotein-A, mg/L & $\begin{array}{c}234.8 \pm 36.5 \\
\text { bcdeghi }\end{array}$ & $\begin{array}{c}256.9 \pm 39.9 \\
\text { acefghi }\end{array}$ & $\begin{array}{c}438.3 \pm 60.0 \\
\text { abdefi }\end{array}$ & $\begin{array}{c}262.6 \pm 63.7 \\
\text { acefghi }\end{array}$ & $\begin{array}{c}329.0 \pm 53.5 \\
\text { abcdfgh }\end{array}$ & $\begin{array}{c}207.3 \pm 64.1 \\
\text { bcdeghi }\end{array}$ & $\begin{array}{c}446.3 \pm 33.2 \\
\text { abdefi }\end{array}$ & $\begin{array}{c}430.1 \pm 46.2 \\
\text { abdefi }\end{array}$ & $\begin{array}{c}329.3 \pm 63.1 \\
\text { abcdfgh }\end{array}$ & 0.047 \\
\hline $\mathrm{FBG}, \mathrm{mmol} / \mathrm{L}$ & $7.5 \pm 1.6$ & $8.3 \pm 1.7$ & $8.8 \pm 1.8$ & $8.6 \pm 2.2$ & $7.7 \pm 1.0$ & $8.0 \pm 1.8$ & $7.3 \pm 1.5$ & $9.1 \pm 2.5$ & $7.7 \pm 2.1$ & 0.310 \\
\hline Uric acid, umol/L & $380.0 \pm 39.4$ & $390.3 \pm 37.0$ & $414.6 \pm 38.9$ & $383.9 .0 \pm 33.5$ & $442.5 \pm 38.8$ & $385.2 \pm 38.3$ & $415.5 \pm 50.6$ & $339.0 \pm 38.5$ & $358.9 \pm 38.3$ & 0.270 \\
\hline
\end{tabular}

BMI, body mass index; SBP, systolic blood pressure; DBP, diastolic blood pressure; ALT, alanine aminotransferase; AST, aspartate aminotransferase; GGT, gamma glutamyl transpeptidase; ALP, alkaline phosphatase; HDL-cholesterol,

high-density lipoprotein-cholesterol; LDL-cholesterol, low-density lipoprotein-cholesterol; FBG, fasting blood glucose.
${ }^{t}$ Continuous variables are expressed as median with IQR for non-Gaussian distribution. P values were for the ANOVA analysis across the groups, different.

$a, b, c, d, e, f, g, h, i$ - refer to statistic significant after post-hoc multiple comparisons with Bonferroni adjustments when compared with Liver-related diseases group (a), Extrahepatic neoplasms group (b), Cardio-and cerebrovascular diseases group (c), Infectious diseases group (d), Respiratory diseases group (e), Digestive diseases group (f), Renal diseases group (g), Endocrine diseases group (h), and Others (i). 
TABLE 5 | The occurrence of multiple organ dysfunction syndrome (MODS) in patients with NAFLD vs. non-NAFLD.

\begin{tabular}{|c|c|c|c|c|c|c|c|}
\hline \multirow[t]{2}{*}{ Organ dysfunction, $\boldsymbol{n}(\%)$} & \multirow{2}{*}{$\begin{array}{l}\text { NAFLD } \\
(n=2,015)\end{array}$} & \multirow{2}{*}{$\begin{array}{l}\text { Other liver } \\
\text { diseases } \\
(n=1,140)\end{array}$} & \multirow{2}{*}{$\begin{array}{l}\text { No liver } \\
\text { diseases } \\
(n=6,916)\end{array}$} & \multirow[t]{2}{*}{$\boldsymbol{P}$} & \multicolumn{3}{|c|}{ Post-hoc } \\
\hline & & & & & NA vs. OL & NA vs. NL & OL vs. NL \\
\hline Heart failure & $877(43.5)$ & $412(36.1)$ & $2,185(31.6)$ & $<0.001$ & $<0.001$ & $<0.001$ & 0.006 \\
\hline Respiratory failure & $885(43.9)$ & $405(35.5)$ & $2,248(32.5)$ & $<0.001$ & $<0.001$ & $<0.001$ & 0.102 \\
\hline Renal failure & $655(32.5)$ & $259(22.7)$ & $1,480(21.4)$ & $<0.001$ & $<0.001$ & $<0.001$ & 1.000 \\
\hline Hepatic failure & $266(13.2)$ & $312(27.4)$ & $539(7.8)$ & $<0.001$ & $<0.001$ & $<0.001$ & $<0.001$ \\
\hline Disseminated intravascular coagulation & $254(12.6)$ & $119(10.4)$ & $387(5.6)$ & $<0.001$ & 0.146 & $<0.001$ & $<0.001$ \\
\hline Two organ dysfunctions & $312(15.5)$ & $130(11.4)$ & $657(9.5)$ & $<0.001$ & 0.004 & $<0.001$ & 0.090 \\
\hline MODS & 596 (29.6) & 294 (25.8) & 1,494 (21.6) & $<0.001$ & 0.048 & $<0.001$ & 0.004 \\
\hline
\end{tabular}

NA, NAFLD; OL, Other liver diseases; NL, No liver diseases; MODS, multiple organ dysfunction syndrome.

Chi-squared test for the occurrence of organ dysfunction, which included single, two and multiple organ dysfunction between NAFLD and non-NAFLD.

mortality and compared it with mortality attributable to other liver diseases and no liver diseases. Our analysis revealed that NAFLD was associated with high rates of ischemic heart diseases and liver-related diseases. Death from pneumonia or sepsis was more frequent in NAFLD patients than in other liver disease patients. Moreover, the steatosis degree was also independently associated with liver-related diseases and cardioand cerebrovascular diseases. In addition, the presence of NAFLD was a significant risk factor for multisystem failure in patients who died during hospitalization.

One of the important findings of our study was that NAFLD was associated with the burden of CVD, with a more than $40 \%$ increase in the mortality ratio for CVD among all deaths, and the severity of steatosis independently correlated with these relationships in the Chinese population. It has been recognized that CVDs are the primary cause of mortality in patients with NAFLD; however, results regarding the relationship between NAFLD and the increased risk of clinical cardiovascular events are conflicting. A recent meta-analysis of 25,837 patients from a six-cohort study demonstrated that the risk of clinical cardiovascular events was significantly higher in patients with NAFLD than in those without NAFLD (RR: 1.77; 95\% CI: $1.26-2.48, P<0.001$ ), with a similar shift in both cardiovascular mortality and stroke after subgroup analysis (18). In a more recent longitudinal study with a 10 -year follow-up in southern Asia, a lack of an association between NAFLD and cardiovascular mortality was reported (19). Another prospective cohort study of 612 patients with clinical indications for coronary angiography in Hong Kong showed that fatty liver could not predict death due to CVD (28). The heterogeneous conclusions among studies can be attributed to several reasons. First, the endpoints in the other studies focused on the incidence instead of the mortality attributable to CVD in NAFLD participants (29-31). Using CVD-related mortality as an outcome may reveal a final prognosis of NAFLD in the real world. Moreover, the increased risk of CVD caused by NAFLD is modified by disease extent, such as fibrosis staging or pathologic scores. Our research included the death cases as the study subjects, and it could be assumed that these patients had a more pronounced progression stage than those in cohort studies. Furthermore, metabolic abnormalities are strong cardiovascular risk factors, and the high collection of metabolic risk factors among patients with NAFLD might also account for the increase in coronary artery disease (CAD)-related deaths. Thus, our results indicate that aggressive treatment of NAFLD and other cardiovascular risk factors might be warranted.

Extra liver cancer was the second most common cause of death in our cohort, and among patients with NAFLD, a $12 \%$ increased risk of extra liver cancer was observed. This was similar to observations in other studies across different geographical areas and ethnicities. A recent longitudinal cohort study from the United States with over 20 years of follow-up and more than 10,000 individuals demonstrated that NAFLD was associated with a nearly 2 -fold increased risk of developing cancer (13), with the highest risks for uterine (IRR $=2.3$ ), stomach $(\mathrm{IRR}=2.3)$, pancreatic $(\mathrm{IRR}=2.1)$, and colon cancers $(\mathrm{IRR}=1.8)$. The varied correlation between NAFLD and these types of cancer in our study was mainly due to the limited sample size, population characteristics and cross-sectional study design, and especially a bias caused by death unrelated to cancer. Collectively, these results suggest that the relationship between NAFLD and the clinical burden of cancer warrants further research.

The third most common cause of death among NAFLD patients was liver-related deaths, according to previous reports (20). As opposed to the Caucasian population, liver-specific death ranked as the sixth cause of mortality in our studied population. The considerable discordance in the ratio of liverrelated outcomes between populations in China and developed countries may result from variations in nutrition and lifestyle determinants that drive hepatic inflammation and fibrogenesis (32). Notably, Western diets contain much higher proportions of fat, fructose, and red meat than the traditional Chinese dietary pattern (characterized by refined grains, vegetables, pork, poultry, and fruits) (33). Western diets promote excess lipid genesis in hepatocytes and therefore induce lipoapoptosis and disease escalation. However, with the changes from a traditional agricultural society to an industrialized urbanized society in the past decades, modern Chinese dietary patterns tend to be similar to westernized diets in part. Therefore, the liver-related mortality 
rate associated with NAFLD in China might lag behind a shift in socioeconomic status.

When analyzing the characteristics of NAFLD-related deaths, we first observed that NAFLD patients suffered from a higher rate of multiple organ failure than those without liver disease and the end of life. It has been increasingly acknowledged that NAFLD may be accompanied by obesity, insulin resistance, diabetes and a chronic system inflammatory state, which has been linked to multiple complications, including communityacquired pneumonia, chronic obstructive pulmonary disease and kidney injuries $(4,5,7)$. Inflammation plays a critical role in initiating and auto amplifying organ failure (34). Furthermore, a steatosis liver, especially in the non-alcoholic steatohepatitis (NASH) stage, releases several proinflammatory cytokines, such as interleukin-1, interleukin-6 and tumor necrosis factors, involved in the activation of deleterious inflammatory pathways. Thus, our data provide important evidence that NAFLD might be an additional predictor of the development of multiorgan failure, and intensive prevention should be implemented.

The limitations of our study should be noted. Our retrospective design and hospital-based data may introduce unavoidable bias. It is possible that in clinical practice many hospitalized patients were not routinely evaluated with any liver imaging during hospitalization. Thus, selection bias for the categorization of the study groups highly potential developed in this study. Second, the cross-sectional analysis could not identify the impact of the progression or regression of NAFLD on disease-specific death causes. Third, to evaluate the effect of steatosis on the distribution of cause of death, we used ultrasonographic features for the grading of hepatic steatosis, which were interpreted by several sonographers from the medical records. That might cause interpersonal variability for interpretation of liver findings. Another major drawback was that we used US to diagnose and stratify the severity of NAFLD, without histological confirmation. However, the histological confirmation of NAFLD in a large general population may be impractical.

\section{CONCLUSION}

In conclusion, our large, regional survey showed that patients with NAFLD in China had a distinct mortality pattern. High mortality attributable to CVD and multiorgan failure occurred in NAFLD patients. Controlling NAFLD may provide benefits in lowering the burden of associated compilations.

\section{REFERENCES}

1. Wong GL, Wong VW. Non-alcoholic fatty liver disease in Asia: how is it different from the West? J Gastroenterol Hepatol. (2019) 34:12678. doi: $10.1111 /$ jgh. 14813

2. Caruso MG, Veronese N, Notarnicola M, Cisternino AM, Reddavide R, Inguaggiato R, et al. Fatty liver and mortality: a cohort population study in South Italy. BMJ Open. (2019) 9:e027379. doi: 10.1136/bmjopen-2018-027379

\section{DATA AVAILABILITY STATEMENT}

The raw data supporting the conclusions of this article will be made available by the authors, without undue reservation.

\section{ETHICS STATEMENT}

The studies involving human participants were reviewed and approved by Clinical Research Ethics Committee of the First Affiliated Hospital of Sun Yat-sen University, the First Affiliated Hospital of Guangzhou Medical University, and the Affiliated Dongguan People's Hospital of Southern Medical University. The patients/participants provided their written informed consent to participate in this study. Written informed consent was obtained from the individual(s) for the publication of any potentially identifiable images or data included in this article.

\section{AUTHOR CONTRIBUTIONS}

BZ and JY: conceive, design, and critical revision of the manuscript for important intellectual content. YL, XG, and XL: data collection, analysis, and manuscript drafting. ML, TW, CS, QM, and FL: data collection. All authors have read and approved the final manuscript.

\section{FUNDING}

This study was funded by Chinese Foundation for Hepatitis Prevention and Control (TQGB20140083), Guangdong Science and Technology Department (2013B021800290, 2014A020212118, and 2017A020215015), National Natural Science Foundation of China (81870404, 81670518, and 81170392), Special Project on the Integration of Industry, Education and Research of Guangzhou, China (201604020155), and Medical Scientific Research Foundation of Guangdong Province (A2019496).

\section{ACKNOWLEDGMENTS}

We are grateful to Professor Aihua Lin in The Public Health School of Sun Yat-sen University for her assistance in statistical analysis of this study.

\section{SUPPLEMENTARY MATERIAL}

The Supplementary Material for this article can be found online at: https://www.frontiersin.org/articles/10.3389/fmed. 2020.584396/full\#supplementary-material

3. Kim D, Adejumo AC, Yoo ER, Iqbal U, Li AA, Pham EA, et al. Trends in mortality from extrahepatic complications in patients with chronic liver disease. from 2007 through 2017. Gastroenterology. (2019) 157:105566. doi: 10.1053/j.gastro.2019.06.026

4. Golabi P, Paik J, Reddy R, Bugianesi E, Trimble G, Younossi ZM. Prevalence and long-term outcomes of non-alcoholic fatty liver disease among elderly individuals from the United States. BMC Gastroenterol. (2019) 19:56. doi: 10.1186/s12876-019-0972-6 
5. Liu HH, Cao YX, Sun D, Jin JL, Guo YL, Wu NQ, et al. Impact of non-alcoholic fatty liver disease on cardiovascular outcomes in patients with stable coronary artery disease: a matched case-control study. Clin Transl Gastroenterol. (2019) 10:e00011. doi: 10.14309/ctg.0000000000000011

6. Houghton D, Zalewski P, Hallsworth K, Cassidy S, Thoma C, Avery L, et al. The degree of hepatic steatosis associates with impaired cardiac and autonomic function. J Hepatol. (2019) 70:1203-13. doi: 10.1016/j.jhep.2019.01.035

7. Önnerhag K, Dreja K, Nilsson PM, Lindgren S. Increased mortality in non-alcoholic fatty liver disease with chronic kidney disease is explained by metabolic comorbidities. Clin Res Hepatol Gastroenterol. (2019) 43:54250. doi: 10.1016/j.clinre.2019.02.004

8. Croci I, Coombes JS, Bucher Sandbakk S, Keating SE, Nauman J, Macdonald GA, et al. Non-alcoholic fatty liver disease: prevalence and all-cause mortality according to sedentary behavior and cardiorespiratory fitness. Prog Cardiovasc Dis. (2019) 62:127-34. doi: 10.1016/j.pcad.2019.01.005

9. Viglino D, Plazanet A, Bailly S, Benmerad M, Jullian-Desayes I, Tamisier R, et al. Impact of non-alcoholic fatty liver disease on long-term cardiovascular events and death in chronic obstructive pulmonary disease. Sci Rep. (2018) 8:16559. doi: 10.1038/s41598-018-34988-2

10. Nseir WB, Mograbi JM, Amara AE, Abu Elheja OH, Mahamid MN. Non-alcoholic fatty liver disease and 30-day all-cause mortality in adult patients with community-acquired pneumonia. QJM. (2019) 112:959. doi: 10.1093/qjmed/hcy227

11. Nseir W, Amara A, Farah R, Ahmad HS, Mograbi J, Mahamid M. Nonalcoholic fatty liver disease is associated with recurrent urinary tract infection in premenopausal women independent of metabolic syndrome. Isr Med Assoc J. (2019) 21:386-9.

12. Kim YK, Kwon OS, Her KH. The grade of nonalcoholic fatty liver disease is an independent risk factor for gallstone disease: an observational study. Medicine. (2019) 98:e16018. doi: 10.1097/MD.0000000000016018

13. Allen AM, Hicks SB, Mara KC,Larson JJ, Therneau TM. The risk of incident extrahepatic cancers is higher in nonalcoholic fatty liver disease than obesity - a longitudinal cohort study. J Hepatol. (2019) 71:122936. doi: 10.1016/j.jhep.2019.08.018

14. Unalp-Arida A, Ruhl CE. Liver fat scores predict liver disease mortality in the United States population. Aliment Pharmacol Ther. (2018) 48:100316. doi: 10.1111/apt.14967

15. Huang Y, Joseph J, de Boer WB. Long-term liver-related outcomes of patients with chronic liver diseases in Australia. Clin Gastroenterol Hepatol. (2020) 18:496-504. doi: 10.1016/j.cgh.2019.07.013

16. Younossi Z, Stepanova M, Ong JP, Jacobson IM, Bugianesi E, Duseja A, et al. Nonalcoholic steatohepatitis is the fastest growing cause of hepatocellular carcinoma in liver transplant candidates. Clin Gastroenterol Hepatol. (2019) 17:748-55. doi: 10.1016/j.cgh.2018.05.057

17. Musso G, Gambino R, Cassader M, Pagano G. Meta-analysis: natural history of non-alcoholic fatty liver disease (NAFLD) and diagnostic accuracy of noninvasive tests for liver disease severity. Ann Med. (2011) 43:61749. doi: $10.3109 / 07853890.2010 .518623$

18. Haddad TM, Hamdeh S, Kanmanthareddy A, Alla VM. Nonalcoholic fatty liver disease and the risk of clinical cardiovascular events: a systematic review and meta-analysis. Diabetes Metab Syndr. (2017) 11(Suppl. 1):S20916. doi: 10.1016/j.dsx.2016.12.033

19. Niriella MA, Kasturiratne A, Beddage TU, Withanage SA, Goonatilleke DC, Abeysinghe CP, et al. Metabolic syndrome, but not non-alcoholic fatty liver disease, increases 10-year mortality: a prospective, community-cohort study. Liver Int. (2020) 40:101-6. doi: 10.1111/liv.14237

20. Li J, Zou B, Yeo YH, Feng Y, Xie X, Lee DH, et al. Prevalence, incidence, and outcome of non-alcoholic fatty liver disease in Asia, 1999-2019: a systematic review and meta-analysis. Lancet Gastroenterol Hepatol. (2019) 4:389-98. doi: 10.1016/S2468-1253(19)30039-1

21. Estes C, Anstee QM, Arias-Loste MT, Bantel H, Bellentani S, Caballeria J, et al. Modeling NAFLD disease burden in China, France, Germany, Italy,
Japan, Spain, United Kingdom, and United States for the period 2016-2030. J Hepatol. (2018) 69:896-904. doi: 10.1016/j.jhep.2018.05.036

22. Kleiner DE, Brunt EM, Natta MV, Behling C, Contos MJ, Cummings OW, et al. Design and validation of a histological scoring system for nonalcoholic fatty liver disease. Hepatology. (2005) 41:1313-21. doi: 10.1002/hep.20701

23. Brunt EM, Kleiner DE, Wilson LA, Belt P, Neuschwander-Tetri BA, NASH Clinical Research Network (CRN). Nonalcoholic fatty liver disease (NAFLD) activity score and the histopathologic diagnosis in NAFLD: distinct clinicopathologic meanings. Hepatology. (2011) 53:810-20. doi: 10.1002/hep. 24127

24. Brunt EM, Janney CG, Di Bisceglie AM, NeuschwanderTetri BA, Bacon BR, et al. Nonalcoholic steatohepatitis: a proposal for grading and staging the histological lesions. Am J Gastroenterol. (1999) 94:2467-74. doi: 10.1111/j.1572-0241.1999.0 1377.x

25. Vilar-Gomez E, Calzadilla-Bertot L, Wong VW, Castellanos M, Fuente RA, Metwally M, et al. Fibrosis severity as a determinant of causespecific mortality in patients with advanced nonalcoholic fatty liver disease: a multi-national cohort study. Gastroenterology. (2018) 155:44357. doi: 10.1053/j.gastro.2018.04.034

26. Alberti KG, Eckel RH, Grundy SM, Zimmet PZ, Cleeman JI, Donato KA, et al. Harmonizing the metabolic syndrome: a joint interim statement of the International Diabetes Federation task force on epidemiology and prevention; national heart, lung, and blood institute; American Heart Association; World Heart Federation; International Atherosclerosis Society; and International Association for the study of obesity. Circulation. (2009) 120:1640-45. doi: 10.1161/CIRCULATIONAHA.109.192644

27. Vilar-Gomez E, Chalasani N. Non-invasive assessment of non-alcoholic fatty liver disease: clinical prediction rules and blood-based biomarkers. J Hepatol. (2018) 68:305-15. doi: 10.1016/j.jhep.2017.11.013

28. Wong VW, Wong GL, Yip GW, Lo AO, Limquiaco J, Chu WC, et al. Coronary artery disease and cardiovascular outcomes in patients with non-alcoholic fatty liver disease. Gut. (2011) 60:1721-27. doi: 10.1136/gut.2011.242016

29. Brunner KT, Pedley A, Massaro JM, Hoffmann U, Benjamin EJ, Long MT. Increasing liver fat is associated with incident cardiovascular risk factors. Clin Gastroenterol Hepatol. (2020) 18:1884-6. doi: 10.1016/j.cgh.2019.08.003

30. Choudhary NS, Duseja A. Screening of cardiovascular disease in nonalcoholic fatty liver disease: whom and how? J Clin Exp Hepatol. (2019) 9:50614. doi: 10.1016/j.jceh.2019.02.005

31. Sinn DH, Kang D, Chang Y, Ryu S, Cho SJ, Paik SW, et al. Nonalcoholic fatty liver disease and the incidence of myocardial infarction: a cohort study. $J$ Gastroenterol Hepatol. (2020) 35:833-9. doi: 10.1111/jgh.14856

32. Schuppan D, Surabattula R, Wang XY. Determinants of fibrosis progression and regression in NASH. J Hepatol. (2018) 68:23850. doi: 10.1016/j.jhep.2017.11.012

33. Li M, Shi Z. Dietary pattern during 1991-2011 and its association with cardio metabolic risks in Chinese adults: the china health and nutrition survey. Nutrients. (2017) 9:1218. doi: 10.3390/nu9111218

34. Linkermann A, Stockwell BR, Krautwald S, Anders HJ. Regulated cell death and inflammation: an auto-amplification loop causes organ failure. Nat Rev Immunol. (2014) 14:759-67. doi: 10.1038/nri3743

Conflict of Interest: The authors declare that the research was conducted in the absence of any commercial or financial relationships that could be construed as a potential conflict of interest.

Copyright (c) $2021 \mathrm{Lin}$, Gong, Li, Shao, Wu, Li, Li, Ma, Ye and Zhong. This is an open-access article distributed under the terms of the Creative Commons Attribution License (CC BY). The use, distribution or reproduction in other forums is permitted, provided the original author(s) and the copyright owner(s) are credited and that the original publication in this journal is cited, in accordance with accepted academic practice. No use, distribution or reproduction is permitted which does not comply with these terms. 